\title{
In vitro effects of photodynamic therapy induced by chloroaluminum phthalocyanine nanoemulsion
}

\author{
Leonardo Pereira Franchi ${ }^{a}$, Camila F. Amantino ${ }^{a}$, Maryanne T. Melo a \\ Ana Paula de Lima Montaldi ${ }^{\mathrm{b}}$, Fernando L. Primo ${ }^{\mathrm{c}}$, Antonio Claudio Tedesco ${ }^{\mathrm{a}, *}$ \\ a Department of Chemistry, Faculty of Philosophy, Sciences and Letters of Ribeirão Preto, USP, Ribeirão Preto, SP, Brazil \\ b Department of Biology, Faculty of Philosophy, Sciences and Letters of RibeirãoPreto, USP, Ribeirão Preto, SP, Brazil \\ ${ }^{\mathrm{c}}$ Department of Bioprocess and Biotechnology, School of Pharmaceutical Sciences of Araraquara, UNESP, Araraquara, SP, Brazil
}

\section{A R T I C L E I N F O}

\section{Article history:}

Received 30 July 2016

Received in revised form 30 August 2016

Accepted 4 September 2016

Available online 7 September 2016

\section{Keywords:}

Cytotoxicity

Flow cytometry

Chloroaluminum phthalocyanine

DNA repair

Cancer cell lines

\begin{abstract}
A B S T R A C T
Background: The photodynamic therapy (PDT) has been used to treat cancer mainly by inducing oxidative stress. Our aim was to evaluate the effect of PDT and its combination with methoxyamine (MX), a blocker of base excision repair (BER), in cells expressing high levels of the APE1 protein, which is involved in cell oxidative damage response.

Methods: The HeLa and A549 cells were treated for $3 \mathrm{~h}$ with chloroaluminum phthalocyanine incorporated into a well-designed nanoemulsion (ClAlPc/NE); and then irradiated by visible light (@670 nm) with doses of $0.1,0.5$ and $1.0 \mathrm{~J} / \mathrm{cm}^{2}$. A simultaneous combination of $\mathrm{MX}+\mathrm{ClAlPc} / \mathrm{NE}$ was performed and then irradiated with the selected dose of $0.5 \mathrm{~J} / \mathrm{cm}^{2}$. The treatments were evaluated in terms of viability, clonogenicity, DNA fragmentation, and cell death mechanism by apoptosis and/or necrosis.

Results: The APE1 protein expression observed was higher in HeLa than in A549. Both cell lines exhibited substantial differences in cell cytotoxicity. The PDT decreased the clonogenicity of HeLa by inducing apoptosis (sub-G1 and annexin detection). Additionaly, the MX potentiates the PDT-effects in HeLa. Otherwise, low cytotoxicity was observed in A549 cells.

Conclusion: The PDT induced apoptosis in high APE1 expressive HeLa cells, and the blockage of BER by MX increased its effects.
\end{abstract}

(c) 2016 Elsevier B.V. All rights reserved.

\section{Background}

The photodynamic therapy (PDT) has become an emerging promise to anticancer therapy [1,2]. The chloroaluminum phthalocyanine (ClAlPc) are molecules excited by visible light (@670 nm) which generate reactive oxygen species (ROS) causing oxidative stress [3]. It may be incorporated into a nanoemulsion as a drug delivery system (ClAlPc/NE) and used as photosensitizer in PDT [4]. The oxidative DNA damage is repaired by Base Excision Repair (BER), being its main component, APE1 (apurinic/apyrimidinic endonuclease 1), overexpressed in numerous solid cancers [5]. Methoxyamine (MX) is an organic amine that interrupts BER by

\footnotetext{
* Corresponding author at: Center of Nanotechnology and Tissue Engineer, Photobiology and Photomedicine Research Group-Department of Chemistry, Faculty of Philosophy, Sciences and Letters of Ribeirão Preto, University of São Paulo Av Bandeirantes, 3900, Monte Alegre, 14049 900, Ribeirão Preto, SP, Brazil.

E-mail address: atedesco@usp.br (A.C. Tedesco).
}

tightly interacting with the DNA apurinic/apyrimidinic sites [6], which are processed by APE1.

Thus, this study aimed to compare the responses of cell lines with high APE1 protein basal levels (A549 and HeLa) to PDT exposure, as well as, evaluate the influence of BER blockage (PDT plus $\mathrm{MX})$, in order to potentiate the cytotoxicity of this therapy.

\section{Materials and methods}

The GM07492 (human fibroblast cells, Coriell Institute for Medical Research); the A549 (lung adenocarcinoma) and HeLa (cervical adenocarcinoma) cells (both from American Type Culture Collection) were cultured in Ham-F12 + DMEM 1:1 medium, 10\% fetal bovine serum (Cultilab, Brazil), antibiotics (1\%) at $37^{\circ} \mathrm{C}$ in a humidified $5 \% \mathrm{CO}_{2}$-incubator.

The nanoemulsion of ClAlPc is type oil-in-water (o/a) obtained by spontaneous emulsification process and quantified as described by Siqueira-Moura et al. [7]. Briefly, the organic phase with acetone was prepared containing natural soy phospholipids and ClAlPc at $55^{\circ} \mathrm{C}$. Subsequently, this organic solution was added into the 

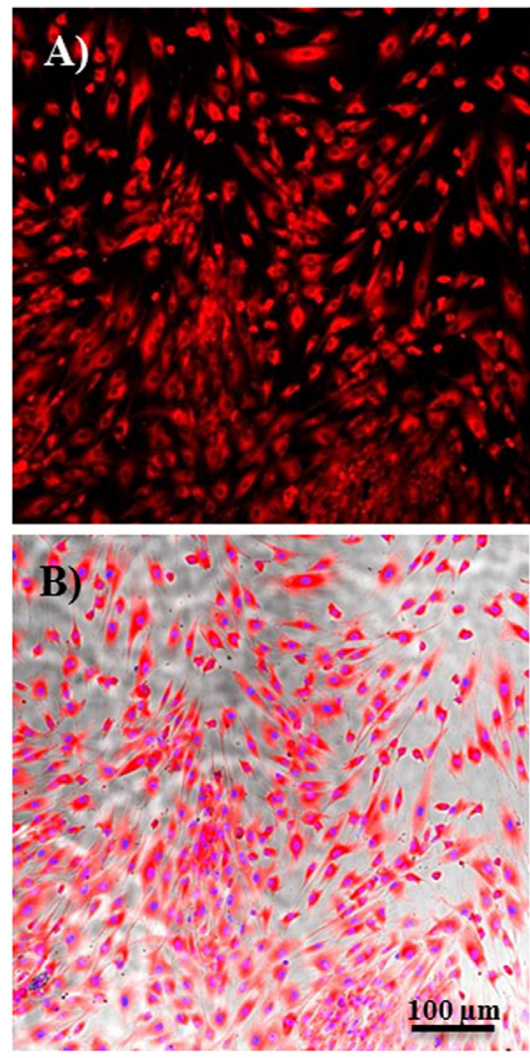

GM07492

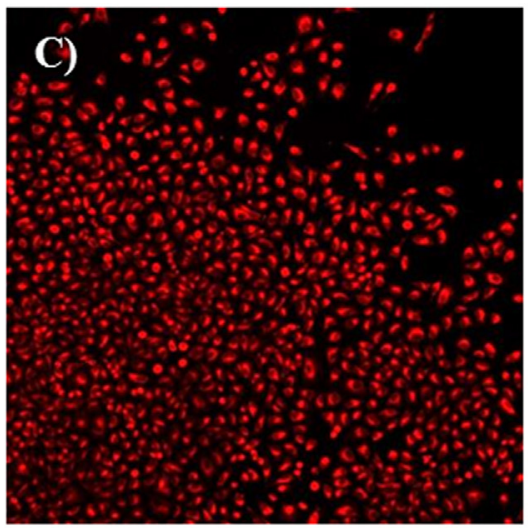

D)

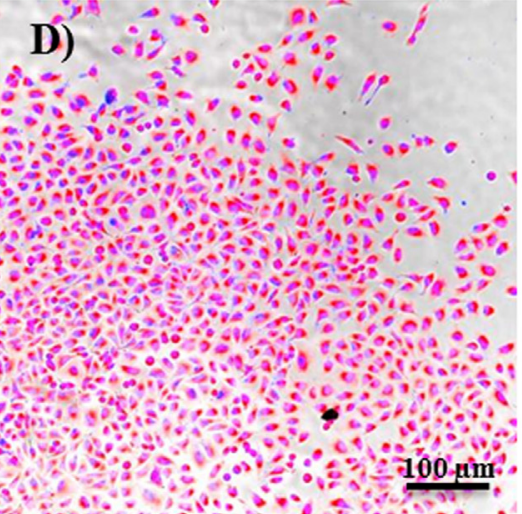

A549
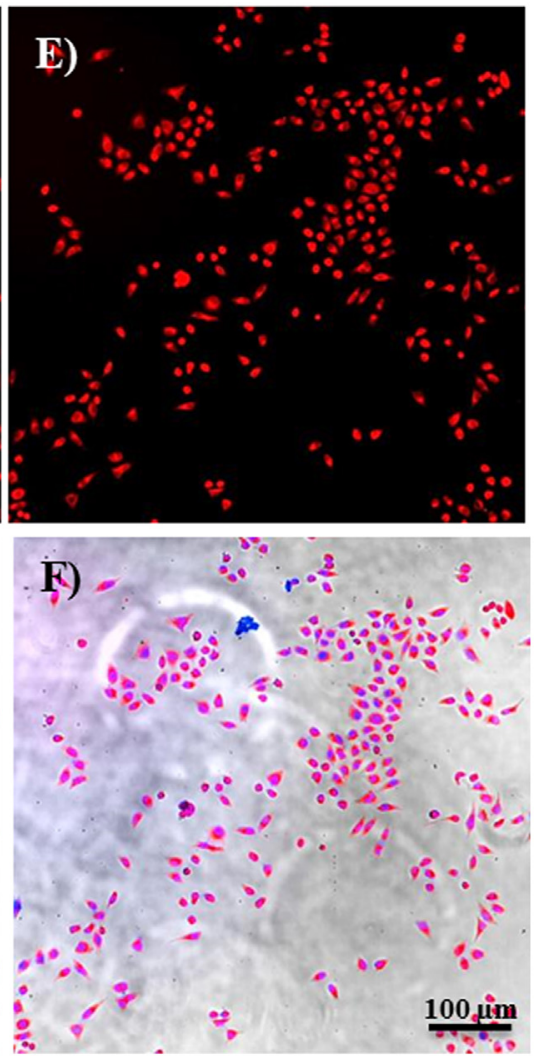

HeLa

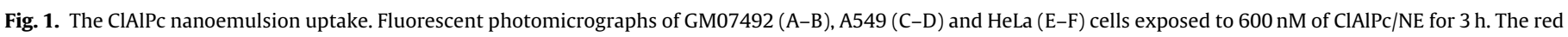
fluorescence indicates the ClAlPc presence inside the cells (A1-C1). The overlay with bright field images are depicted in B-D-F. Scale bar: 100 nm.

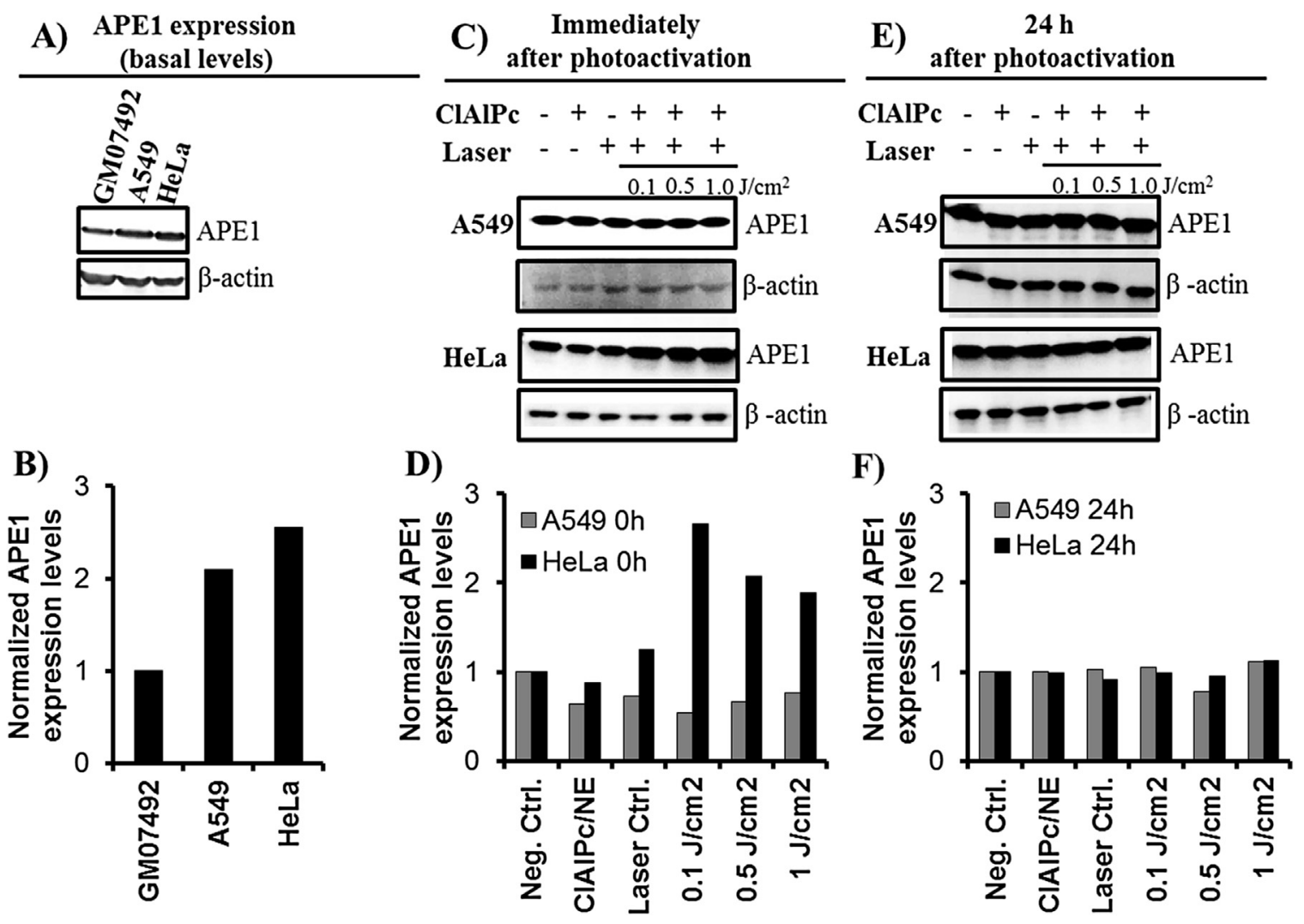

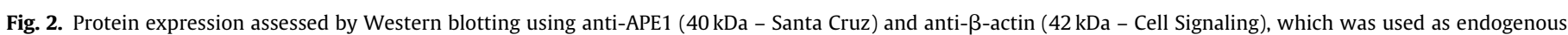

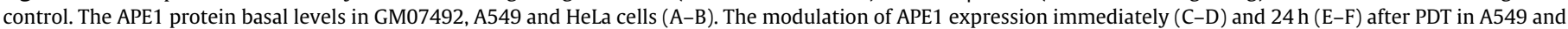
HeLa cells. 
A)

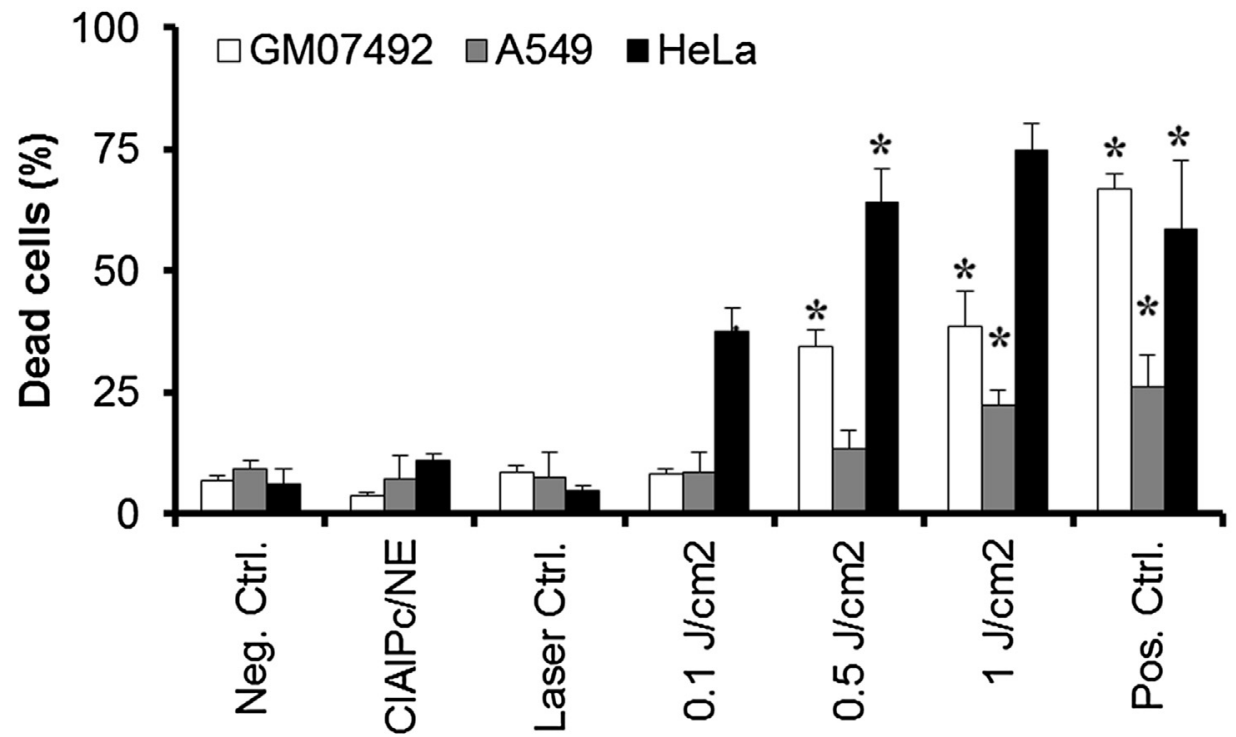

B)

A549

HeLa
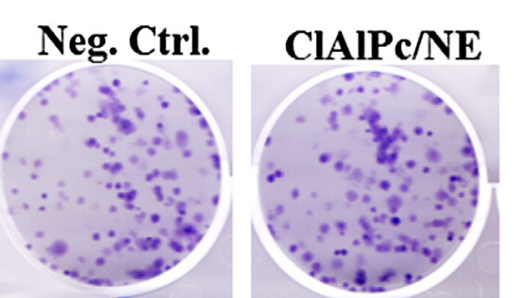

Laser Ctrl.
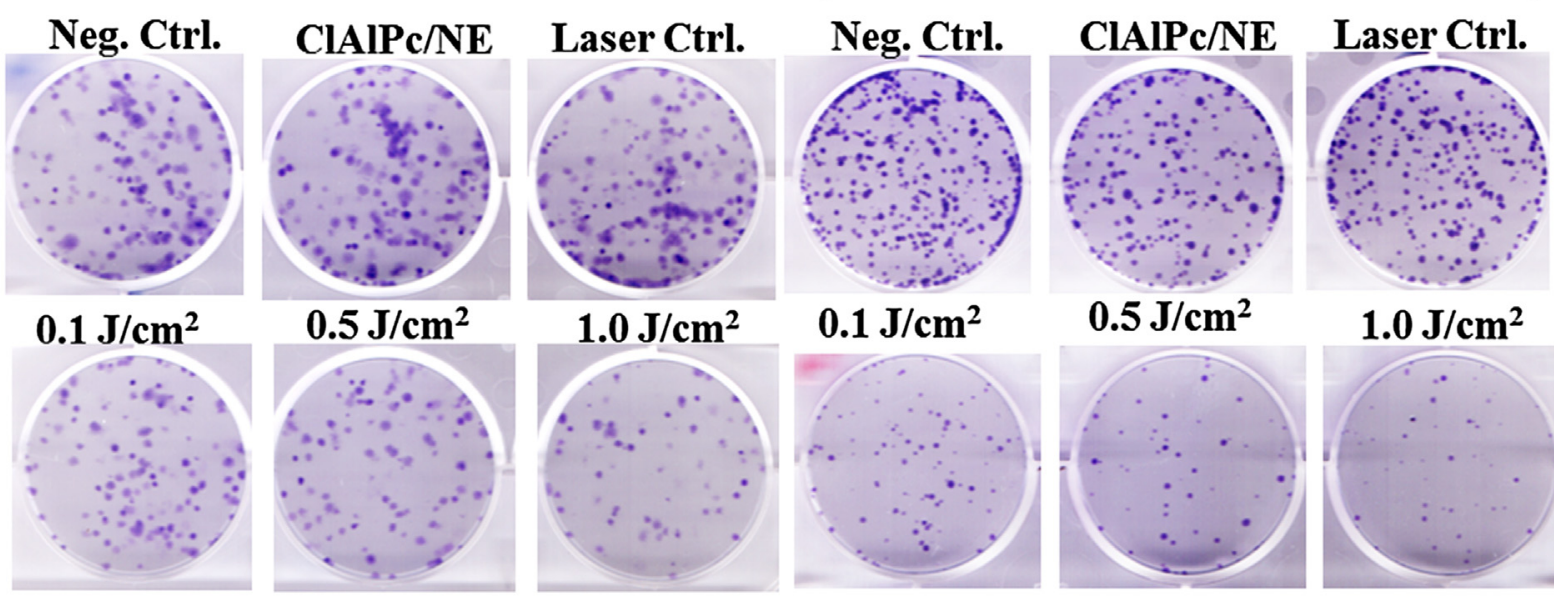

$1.0 \mathrm{~J} / \mathrm{cm}^{2}$

C)

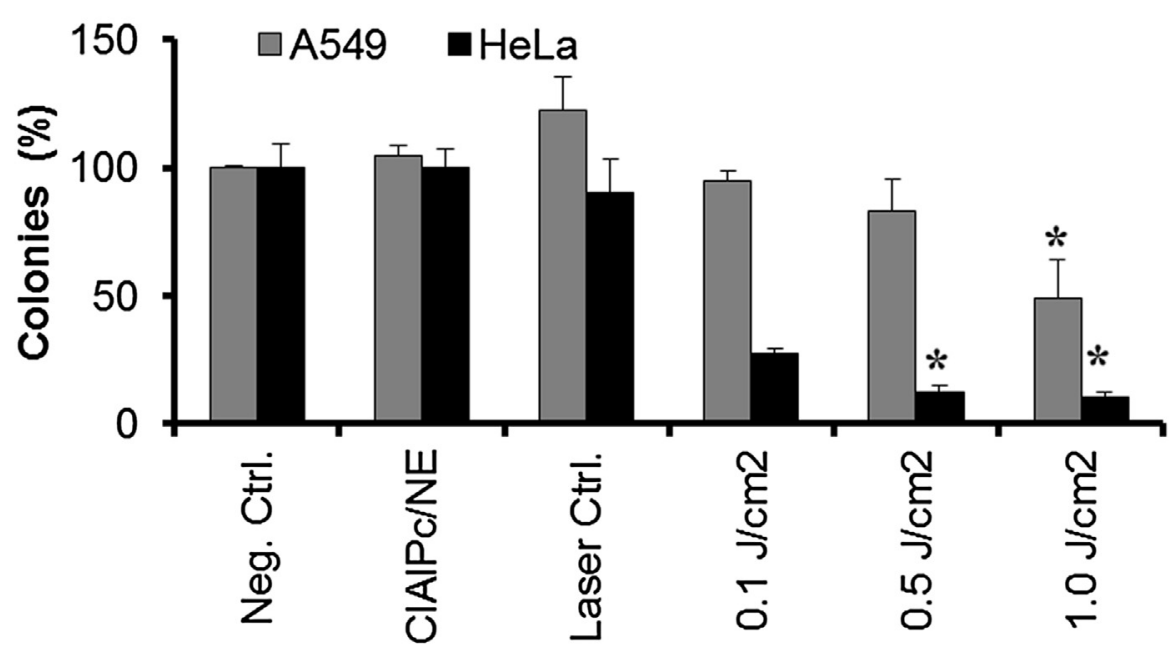

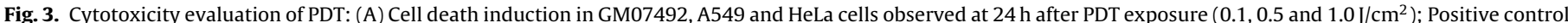

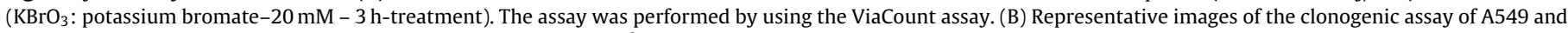

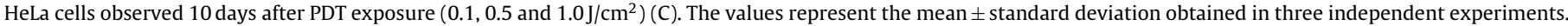

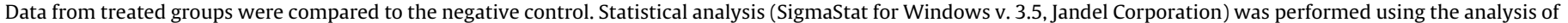
variance (One way ANOVA) test and the $p$ value $<0.05\left(^{*}\right)$ was considered significant using Bonferroni test. 
A)

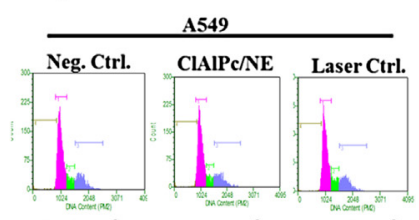

$0.1 \mathrm{~J} / \mathrm{cm}^{2}$
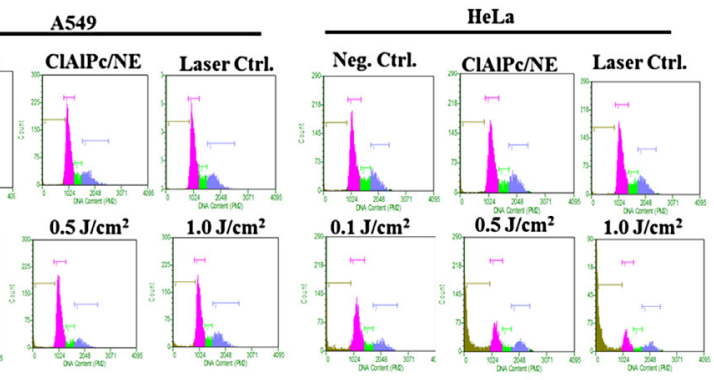

B)

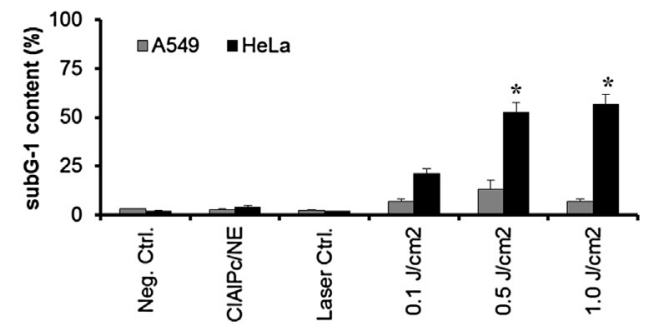

C)
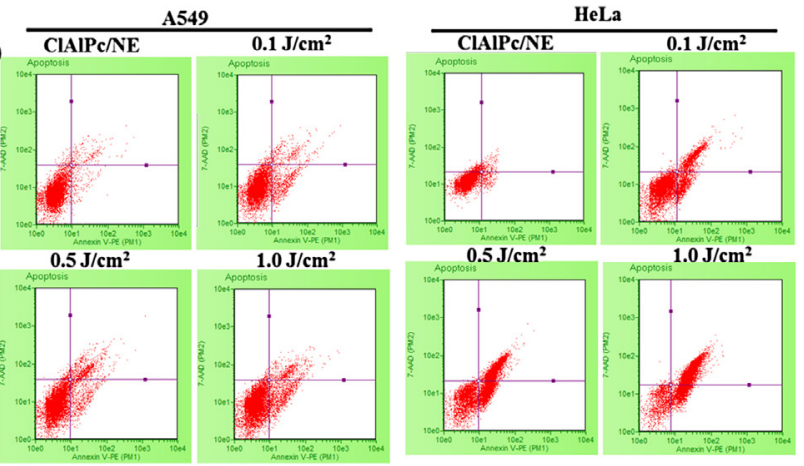

D)

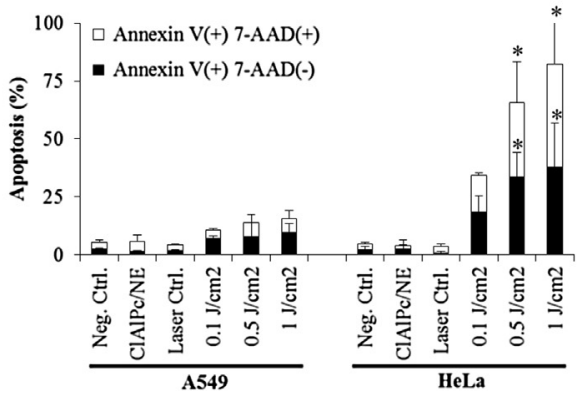

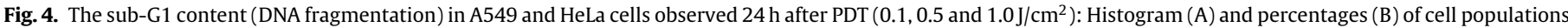

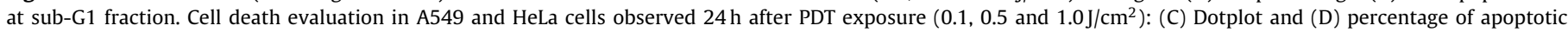

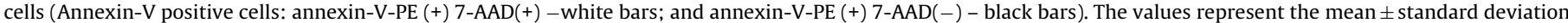

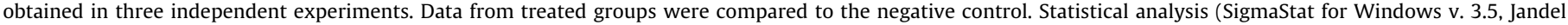
Corporation) was performed using the analysis of variance (One way ANOVA) test and the $p$ value $<0.05\left({ }^{*}\right)$ was considered significant using Bonferroni test.

aqueous phase containing, poloxamer 188 as an anionic surfactant under magnetic stirring. Organic solvent was removed by evaporation under reduced pressure at $60^{\circ} \mathrm{C}$. The volume of the $\mathrm{NE}$ was then concentrated to the aqueous phase $[4,8]$.

We used fluorescence microscopy (High Content Screening, Operetta, PerkinElmer) to detect the uptake of ClAlPc/NE identified as a red fluorescence inside the three cell lines studied $(600 \mathrm{nM}$, 3 h-treatment) (Fig. 1). The APE1 protein expression was detected by Western Blot (Life technologies) as an indicative of BER modulation in response to PDT. And GM07492 cells were used for APE1 expression normalization.The cellular responses after ClAlPc photoactivation, with visible light at $0.1,0.5$ and $1.0 \mathrm{~J} / \mathrm{cm}^{2}$ doses using a diode laser at $670 \mathrm{~nm}$ (Eagle Quantum Tech, Brazil), were evaluated in terns of: cell death by using the cell ViaCount ${ }^{\circledR}$ assay; the ability of cells to form colonies evaluated by clonogenic assay; DNA fragmentation (sub-G1 phase) measured by propidium iodide staining; and detection of necrotic and apoptotic cell death by using the dyes annexin $\mathrm{V}-\mathrm{PE}$ and 7-AAD, following the methods described elsewhere $[9,10]$. The combined treatments were performed simultaneously ( $3 \mathrm{~h}$-incubation, MX-40 mM plus ClAlPc/NE at $0.5 \mathrm{~J} / \mathrm{cm}^{2}$ ) (Reagents from Sigma-Aldrich; flow cytometry assays from MerckMillipore).

\section{Results and conclusions}

The HeLa and A549 cells were chosen because show high levels of basal APE1 protein. In A549 cells, we detect a 2.10-fold higher APE1 protein levels compared to fibroblasts (GM07492), which did not change after ClAlPc-photostimulation (Fig. 2). After PDT exposure we observed in this cell line that only the highest dose $\left(1.0 \mathrm{~J} / \mathrm{cm}^{2} ; p<0.05\right)$ increased cell death (Fig. 3), the clonogenic capacity was reduced only at the highest dose ( $49 \%$ survival rate at $1.0 \mathrm{~J} / \mathrm{cm}^{2} ; p<0.05$ ), and the sub-G1 content (DNA fragmentation) was not increased. In order to distinguish between apoptosis and necrosis, cells were stained with annexin-V/7-AAD. Apoptosis and necrosis were not significantly increased in this cell line.

In relation to HeLa cells, it was detected the highest APE1 protein levels among the cell lines; 2.56-fold compared to GM07492 cells. Moreover, its levels were clearly increased immediately after PDT exposure $\left(2.67,2.08\right.$, and 1.89 -fold at $0.1,0.5$ and $1.0 \mathrm{~J} / \mathrm{cm}^{2}$ doses, respectively) (Fig. 2). A dose-dependent cell death induction was observed in HeLa $\left(37,63\right.$, and $74 \%$ at $0.1,0.5$, and $1.0 \mathrm{~J} / \mathrm{cm}^{2}$, respectively; $p<0.05$ ) (Fig. 3). The clonogenic survival rates were reduced at all doses tested $\left(27,13\right.$, and $10 \%$ at $0.1,0.5$, and $1.0 \mathrm{~J} / \mathrm{cm}^{2}$, respectively; $p<0.05$ ) (Fig. 3). All doses tested also resulted in sub-G1 accumulation $\left(21,52\right.$, and $57 \%$ at $0.1,0.5$ and $1.0 \mathrm{~J} / \mathrm{cm}^{2}$, respectively; $p<0.05$ ). Additionally, apoptosis induction was seen as the main cell death pathway in HeLa cells (total annexin-V positive: 65 and $80 \%$ at 0.5 and $1.0 \mathrm{~J} / \mathrm{cm}^{2}$; respectively; $p<0.05$ ) (Fig. 4).

We also evaluated the BER influence in responses to PDT. The dose $0.5 \mathrm{~J} / \mathrm{cm}^{2}$ was chosen to detect the different responses in the cell lines studied. Moreover, this dose induced $~ 30 \%$ of cell death in GM07492 showing low cytotoxicity to healthy cells (Fig. 3). In A549 cells, only the combination (MX plus PDT) was effective in reducing the clonogenic rate (37\%; $<$ < 0.05) (Fig. 5), however, not induced cell death (Fig. 5), sub-G1 accumulation and apoptosis/necrosis rates (Fig. 6).

On the other hand, in HeLa cells the clonogenic rates decreased from 12 to $6 \%$ in combined treatment. Interesting, the MX tested alone decreased survival rates $(33 \% ; p<0.05)$ showing that BER is an important repair pathway in HeLa cells (Fig. 5). Additionally, the combined treatment increased cell death at $23 \%$ (60 vs. $83 \%$; $p<0.05$ ) (Fig. 5), elevated the sub-G1 content ( $46 \%$ to $62 \% ; p<0.05$ ), which was confirmed by an increment of apoptosis from 45 to $68 \%$ (Fig. 6).

We could observe that PDT did not modify the A549-APE1 protein levels, considering that this cell line was more resistant than HeLa cells, which showed high protein levels after PDT exposure. The NF-E2-related factor 2 (Nrf2), a key transcription regulator for 


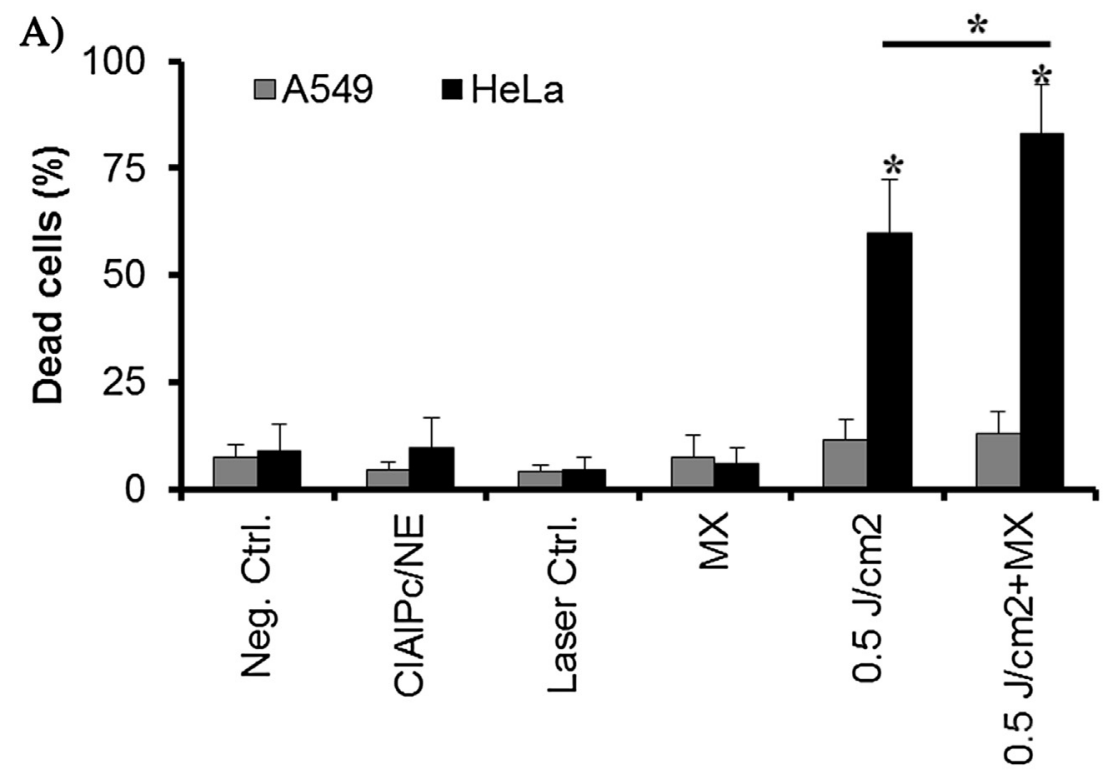

B)

A549

HeLa

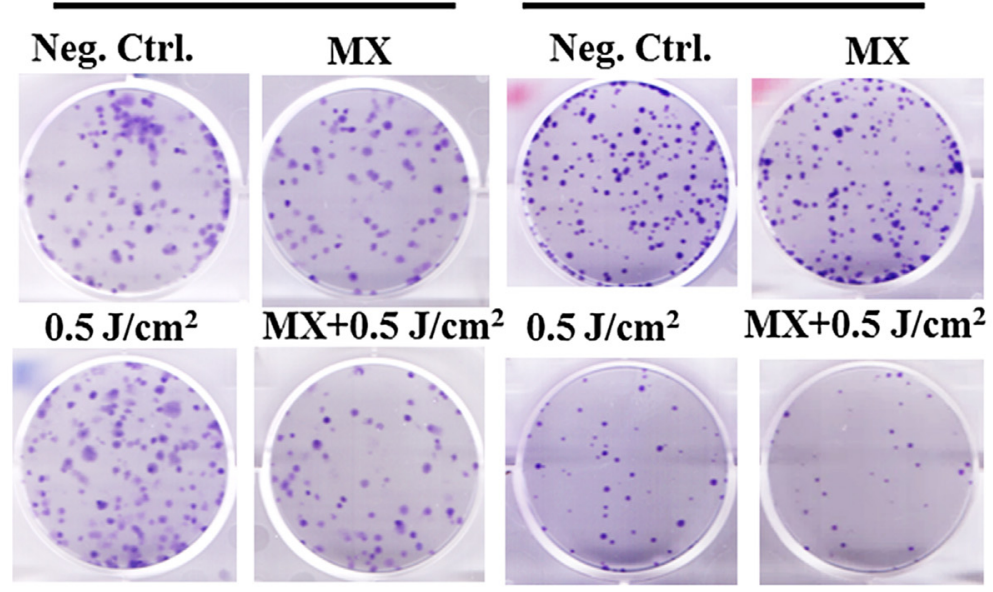

C)

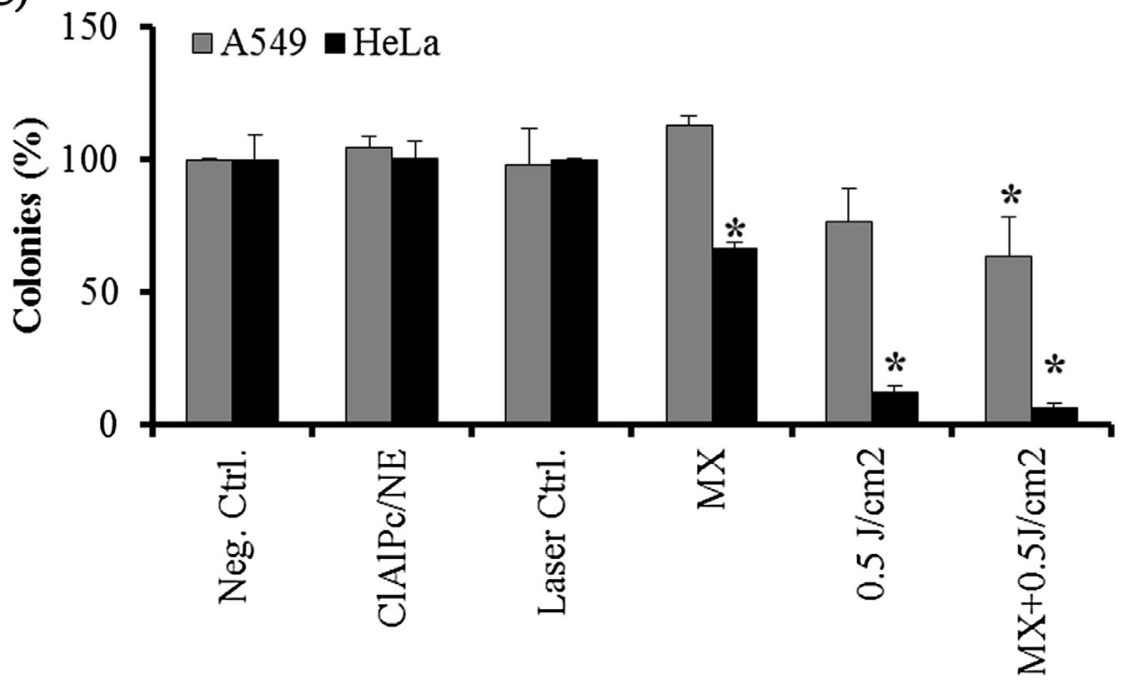

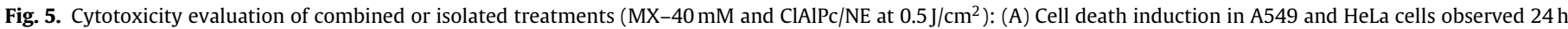

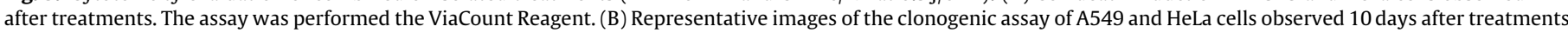

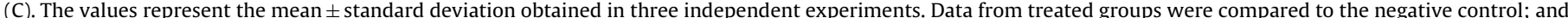

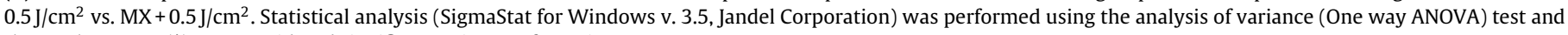
the $p$ value $<0.05\left({ }^{*}\right)$ was considered significant using Bonferroni test. 
A)

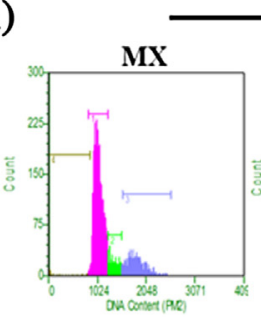

A549

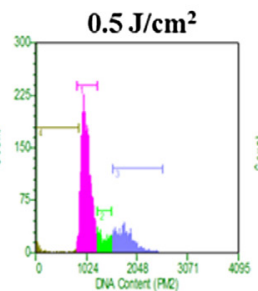

HeLa

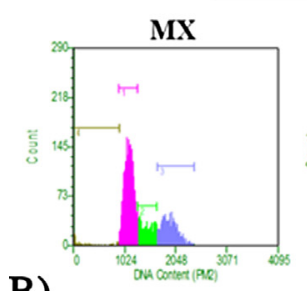

B)
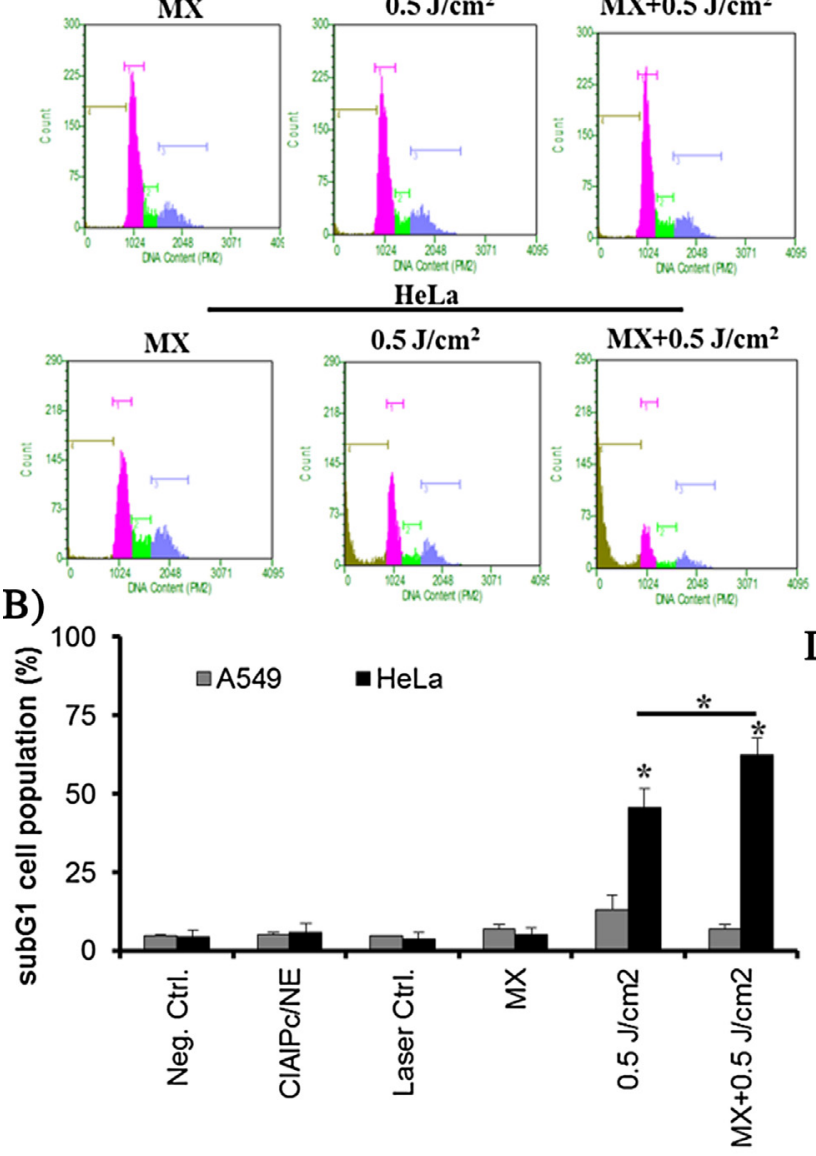

$\mathrm{MX}+0.5 \mathrm{~J} / \mathrm{cm}^{2}$
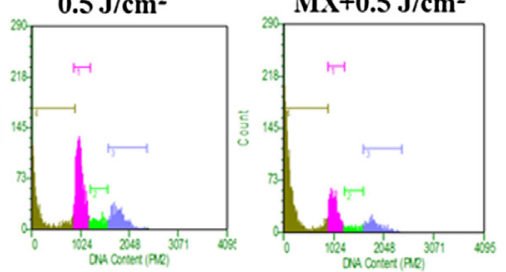

C)

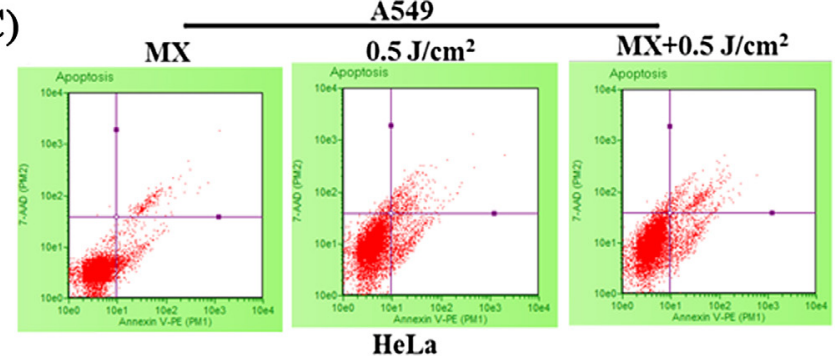

D)

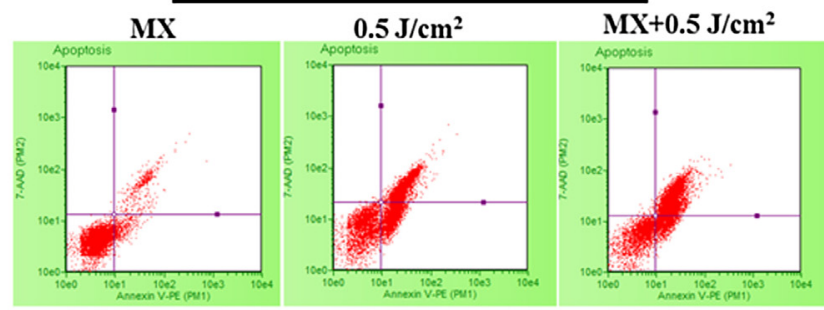

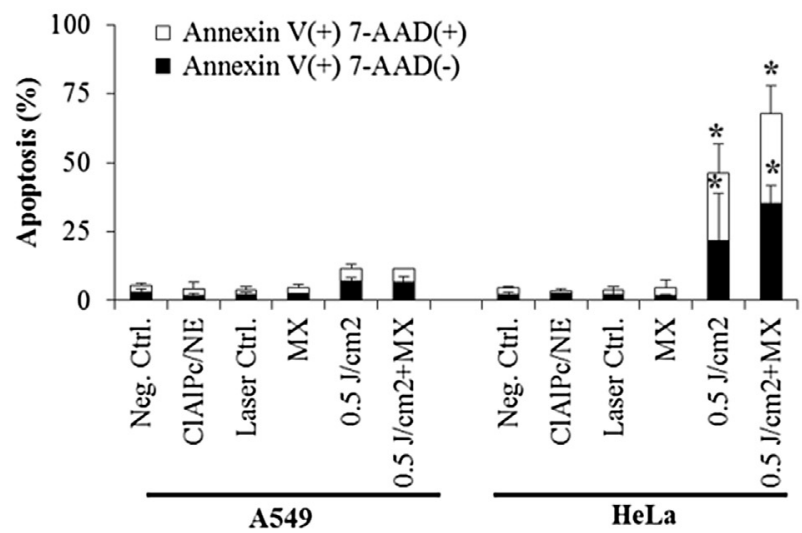

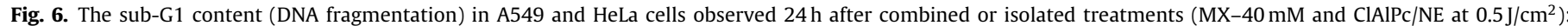

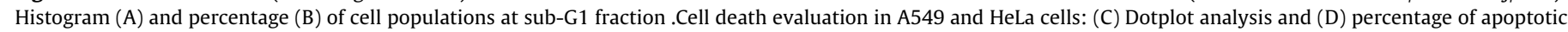

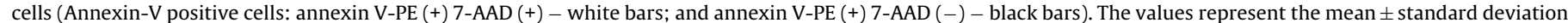

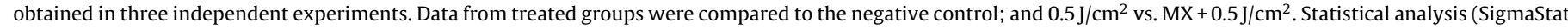

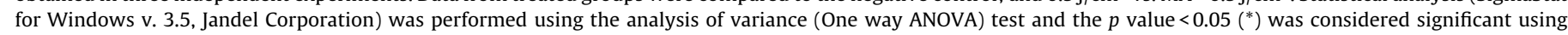
Bonferroni test.

antioxidant and detoxification enzymes, is abundantly expressed in A549 cells and it may be involved in PDT-resistance of this cell line [11].

Nevertheless, MX increased PDT effects in HeLa cells. Therefore, the BER impairment can be considered as a strategy to improve the efficacy of ClAlPc/NE-induced PDT.

\section{Funding}

This research is supported by São Paulo Research Foundation (FAPESP)2014/11870-9, 2013/50181-1 and FINEP 01.10.0758.01.

\section{References}

[1] M.P. Siqueira-Moura, F.L. Primo, E.M. Espreafico, A.C. Tedesco, Development, characterization, and photocytotoxicity assessment on human melanoma of chloroaluminum phthalocyanine nanocapsules, Mater. Sci. Eng. C-Mater. Biol. Appl. 33 (3) (2013) 1744-1752.

[2] H. Mohammadpour, R. Fekrazad, Antitumor effect of combined Dkk-3 and 5-ALA mediated photodynamic therapy in breast cancer cell's colony, Photodiagn. Photodyn. Ther. 14 (2016) 200-203.

[3] R.R. Allison, H.C. Mota, V.S. Bagnato, C.H. Sibata, Bio-nanotechnology and photodynamic therapy-State of the art review, Photodiagn. Photodyn. Ther. 5 (1) (2008) 19-28.

[4] F.L. Primo, M.B.D. Reis, M.A. Porcionatto, A.C. Tedesco, In vitro evaluation of chloroaluminum phthalocyanine nanoemulsion and low-level laser therapy on human skin dermal equivalents and bone marrow mesenchymal stem cells, Curr. Med. Chem. 18 (22) (2011) 3376-3381.

[5] M.L. Fishel, M.R. Kelley, The DNA base excision repair protein Ape1/Ref-1 as a therapeutic and chemopreventive target, Mol. Aspects Med. 28 (3-4) (2007) 375-395.

[6] A.P. Montaldi, E.T. Sakamoto-Hojo, Methoxyamine sensitizes the resistant glioblastoma T98G cell line to the alkylating agent temozolomide, Clin. Exp. Med. 13 (4) (2013) 279-288.

[7] M.P. Siqueira-Moura, F.L. Primo, A.P.F. Peti, A.C. Tedesco, Validated spectrophotometric and spectrofluorimetric methods for determination of chloroaluminum phthalocyanine in nanocarriers, Pharmazie 65 (1) (2010) 9-14.

[8] F.L. Primo, M. Bentley, A.C. Tedesco, Photophysical studies and in vitro skin permeation/retention of foscan (R)/nanoemulsion (NE) applicable to photodynamic therapy skin cancer treatment, J. Nanosci. Nanotechnol. 8 (1) (2008) 340-347.

[9] L.P. Franchi, B.B. Manshian, T.A.J. de Souza, S.J. Soenen, E.Y. Matsubara, J.M. Rosolen, C.S. Takahashi, Cyto- and genotoxic effects of metallic nanoparticles in untransformed human fibroblast, Toxicol. In Vitro 29 (7) (2015) 1319-1331.

[10] T.A.J. Souza, L.P. Franchi, L.R. Rosa, M.A.M.S. da Veiga, C.S. Takahashi, Cytotoxicity and genotoxicity of silver nanoparticles of different sizes in CHO-Kl and CHO-XRS5 cell lines, Mutat. Res.-Genetic Toxicol. Environ. Mutagen. 795 (2016) 70-83.

[11] S. Homma, Y. Ishii, Y. Morishima, T. Yamadori, Y. Matsuno, N. Haraguchi, N. Kikuchi, H. Satoh, T. Sakamoto, N. Hizawa, K. Itoh, M. Yamamoto, Nrf2 enhances cell proliferation and resistance to anticancer drugs in human lung cancer, Clin. Cancer Res. 15 (10) (2009) 3423-3432. 